
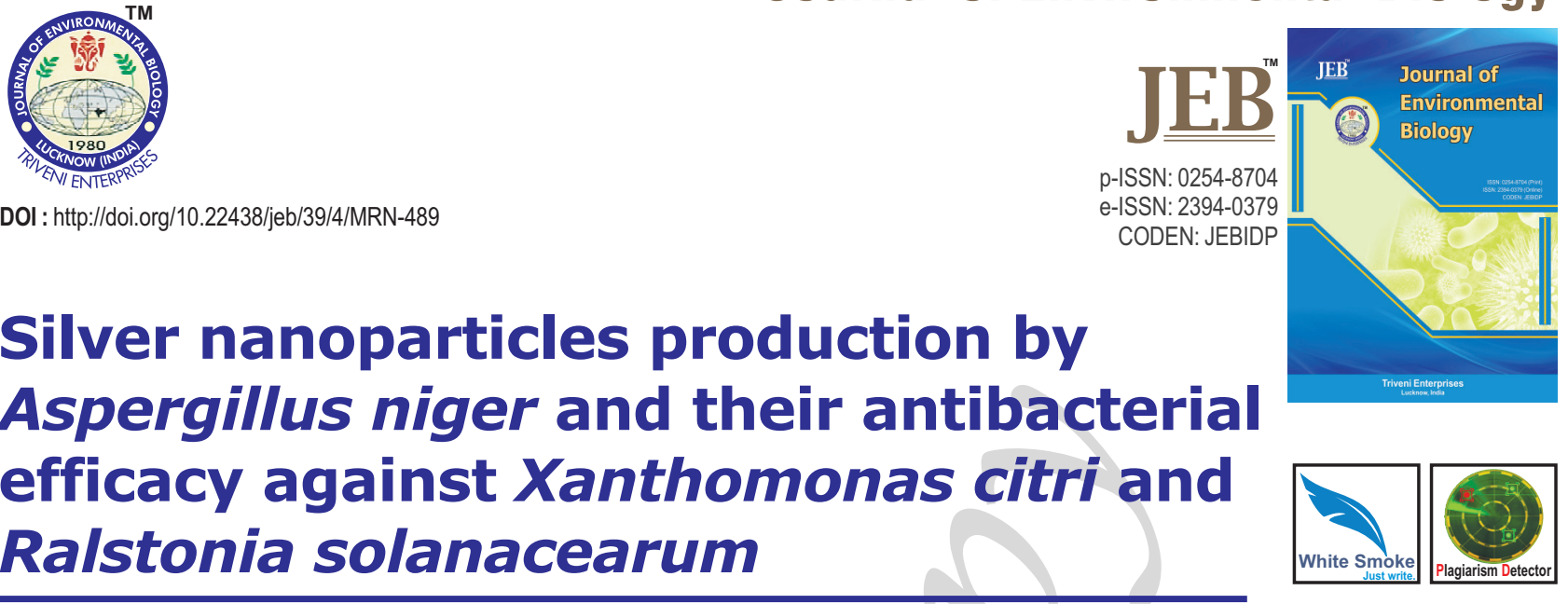

Authors Info

Prameela Devi Thokala*, D. Kamil and R.S. Toppo

Division of Plant Pathology, Indian Agricultural Research Institute, New Delhi -110 012, India

*Corresponding Author Email : prameelancha@yahoo.co.in

Key words

Aspergillus niger

Bioassay

Pathogenic bacteria

Silver nanoparticles

\section{Publication Info}

Paper received: 18.10 .2016

Revised received : 08.03.2017

Re-revised received : 26.09.2017

Accepted:02.11.2017

\section{Abstract}

Aim : Nanobiotechnology is being widely applied in multidisciplinary fields including biopesticide applications. Recently, there is an increase research in the fungal mediated production of silver and copper nanoparticles.

Methodology : In this investigation, the silver nanoparticles were synthesized from the isolates of industrial fungus, Aspergillus niger and their efficacy was examined using well diffusion assay against two phytopathogenic bacteria viz., Xanthomonas citri and Ralstonia solanacearum. The silver nanoparticles developed from Aspergillus niger cell filtrate were described through UVVis spectrophotometer, Transmission electron microscope (TEM) analysis and Fourier Transform Infrared Spectroscope (FTIR).

Results : The production of silver nanoparticles was confirmed by visualization of peak at $420 \mathrm{~nm}$ in UV-Vis spectrophotometer. FTIR studies showed the protein capping of these silver nanoparticles, while TEM microphotographs showed well dispersed silver nanoparticles which are isotropic and round having size between 3-25 nm. The 20-30 mm diameter inhibition zones were formed by biosynthesized silver nanoparticles when tested against Xanthomonas citri and Ralstonia solanacearum.

Interpretation : Aspergillus niger based silver nanoparticles were proved to be used against plant pathogenic bacteria due to their broad spectrum efficacy. Further studies are needed to investigate the efficacy of silver nanoparticles as antibacterial agent in vivo.
$\mathrm{AgNO}_{3}$ solution and Aspergillus culture

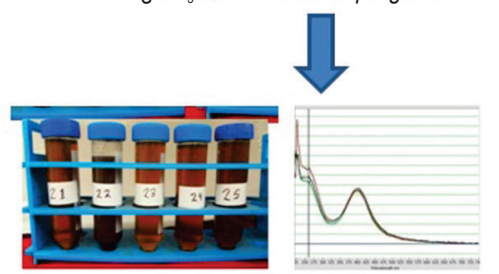

$\mathrm{AgNO}_{3}$ particle from Aspergillus culture
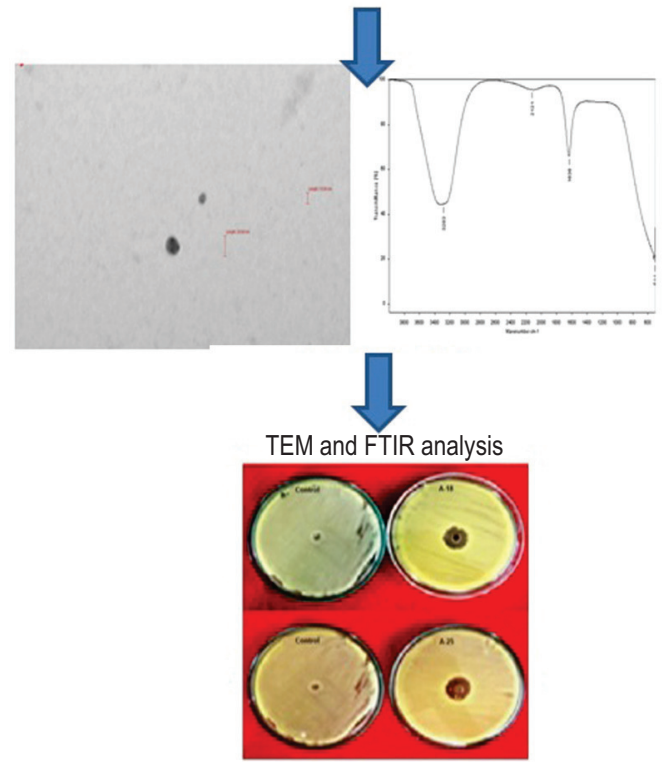

$\mathrm{AgNO}_{3}$ particle effect on bacterial culture

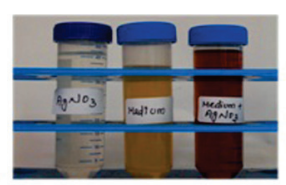




\section{Introduction}

Nanoparticles are the basic units for different nanotechnology applications. The sizes of nanometer dimensions with a range of 1-100 nm determine the properties (physical and chemical) of materials which shows different ways of future applications (Rai et al., 2009). To avoid application of hazardous chemical pesticides, there is a need for the production of environmentally safe nanoparticles. Many organisms produce inorganic materials, either intracellularly or extracellularly (Ahmad et al., 2003: Sastry et al., 2003). Even at high metal ion concentration, different microorganisms can live and grow because of their ability to fight metal stress.

The silver nanoparticles production from living organisms is ecofriendly, safe, cost effective and having effective antibacterial properties. Recently, many microorganisms especially fungi was proved as potential bio-agents for the nanosizing of gold, silver and cadmium metals (Sastry et al., 2003). When the fungi, Beauveria, Verticillium, Fusarium and Trichoderma exposed to silver and gold ions, reduced the metal ion rapidly and formed respective metallic nanoparticles (Bhainsa and D'Souza, 2006: Balaji et al., 2009; Singh and Raja, 2011; Prameeladevi et al., 2013; Kamil et al., 2017). The structural analysis of nanoparticles was done with transmission electron microscope (Balaji et al., 2009; Shaligram et al., 2009).

Nanoparticles are synthesized when the microorganisms grab the metal ions from the environment and turn them into the element metal by the enzymes produced through cell activities. The extracellular biosynthesis of nanoparticles using fungi can also make the downstream processing much easier than bacteria (Li et al., 2011). Silver nanoparticles (AgNPs) are reported as a promising antimicrobial agents which acts on a high range of target sites both extra- and intra-cellularly and exhibited lysis of Gram positive and Gram negative bacteria even multi-resistant strains (Shrivastava et al., 2007; Zeng et al., 2007; Roe et al., 2008) with a size of 10-100 nm (Morones et al. 2005). The bactericidal activity was reported by Rai et al. (2012) against Pseudomonas aeruginosa, Escherichia coli and Staphylococcus aureus and also reported by Verma et al. (2013) against Salmonella, Pseudomonas and Bacillus. Silver nanoparticles synthesized from Fusarium semitectum have been found with strong antibacterial activity against Klebsiella pneumonia and Pseudomonas aeruginosa (Gitanjali and Ashok, 2014).

The extracellular production of silver nanoparticles using Aspergillus fumigatus and Aspergillus flavus was reported by D'Souza (2006). The process of silver nanoparticles synthesis is quick and the reaction starts immediately after metal ions mixed with filtrate (Vigneshwaran et al., 2007). The AgNPs produced using Aspergillus terreus can inhibit Staphylococcus aureu, Pseudomonas aeruginosa and Escherichia coli (Li et al., 2011). The present study was performed for the fungal mediation synthesis of silver nano particles from silver nitrate solution using
Aspergillus niger and to find the antibacterial activity of these produced nanoparticles against Xanthomonas citri and Ralstonia solanacearum.

\section{Materials and Methods}

Preparation of culture filtrate of Aspergillus niger : All the microbial cultures for the work were procured from Indian Type Culture Collection, Division of Plant Pathology, Indian Agricultural Research Institute, New Delhi. All these isolates of the fungi mentioned above were cultured on Potato Dextrose Agar slants (for storage and further use) and Potato Dextrose Broth (for the extracellular synthesis of Ag NPs) and incubated at $25^{\circ} \mathrm{C}$ in BOD incubator for 10 days. The 10-day-old fungal cultures from PDB were transferred into $30 \mathrm{ml}$ tube and then centrifuged (12000 rpm) for half an hour at room temperature. The clear liquid above the sediment was collected and used as a culture filtrate for Ag NPs biosynthesis.

Aspergillus niger mediated synthesis of silver nanoparticles (AgNPs) : For extra cellular production of silver nanoparticles, 50 $\mathrm{ml}$ aqueous solution of $\mathrm{AgNO}_{3}$ was mixed with $50 \mathrm{ml}$ of culture filtrate of $A$. niger in a flask with $8.5 \mathrm{pH}$. The mixer was kept under dark condition at $27^{\circ} \mathrm{C}$ and $200 \mathrm{rpm}$ for 5 days in shaker incubator.

\section{Analysis of silver nanoparticles (AgNPs)}

Spectroscopic studies : The UV-VIS spectrum was visualized at $24 \mathrm{hr}$ interval up to $120 \mathrm{hrs}$ and their absorbance was recorded at $420 \mathrm{~nm}$ using UV-Vis spectrometer.

Transmission electron microscopy studies : The fungal mediated silver nanoparticles were placed on carbon coated $40 \mathrm{X}$ $40 \mu \mathrm{l}$ mesh sized TEM grids and analyzed through electron microscope (JEOL model $1200 \mathrm{EX}$ ) which was operated at $120 \mathrm{kV}$. The observations were noted through photomicrograph.

Fourier transforms infra-red spectroscopy : FT-IR spectra of AgNPs were obtained through Fourier transform infrared (FTIR) spectrophotometer in diffuse reflectance mode at four particles/cm resolution. The AgNPs were ground with the pellets of potassium bromide and examined under FTIR spectrophotometer at $4000-400 \mathrm{~cm}^{-1}$ region.

Extraction of Ag NPs : The mixture of cell debris and silver nanoparticles (AgNPs) was centrifuged for $20 \mathrm{~min}$ at $4500 \mathrm{rpm}$ and $4^{\circ} \mathrm{C}$ and the supernatant was further centrifuged for $30 \mathrm{~min}$ at $14000 \mathrm{rpm}$ and $4^{\circ} \mathrm{C}$ (Chan and Don, 2012). The pellet having NPs were suspended i milli $Q$ water.

Anti bacterial activity of Ag NPs produced using Aspergillus niger : Both the bacterial cultures grown on nutrient agar were inoculated in nutrient broth for further use. AgNPs synthesized by the fungi were tested at $100 \mathrm{ppm}$ for anti-bacterial activity by well diffusion assay against the phyto-pathogenic bacteria viz., 
Xanthomonas citri and Ralstonia solanacearum. In this test, the maximum concentration of bacterial culture was standardized as $300 \mu \mathrm{l}$ and maximum SNP concentration against Xanthomonas citri and Ralstonia solanacearum were standardized as $30 \mu \mathrm{l}$. The pure cultures of Xanthomonas citri and Ralstonia solanacearum $(300 \mu l)$ were inoculated uniformly onto the nutrient agar medium plates. The $6 \mathrm{~mm}$ hole was made at the center of the plate by using Cork borer on the bacterial-cultured plates and impregnated with
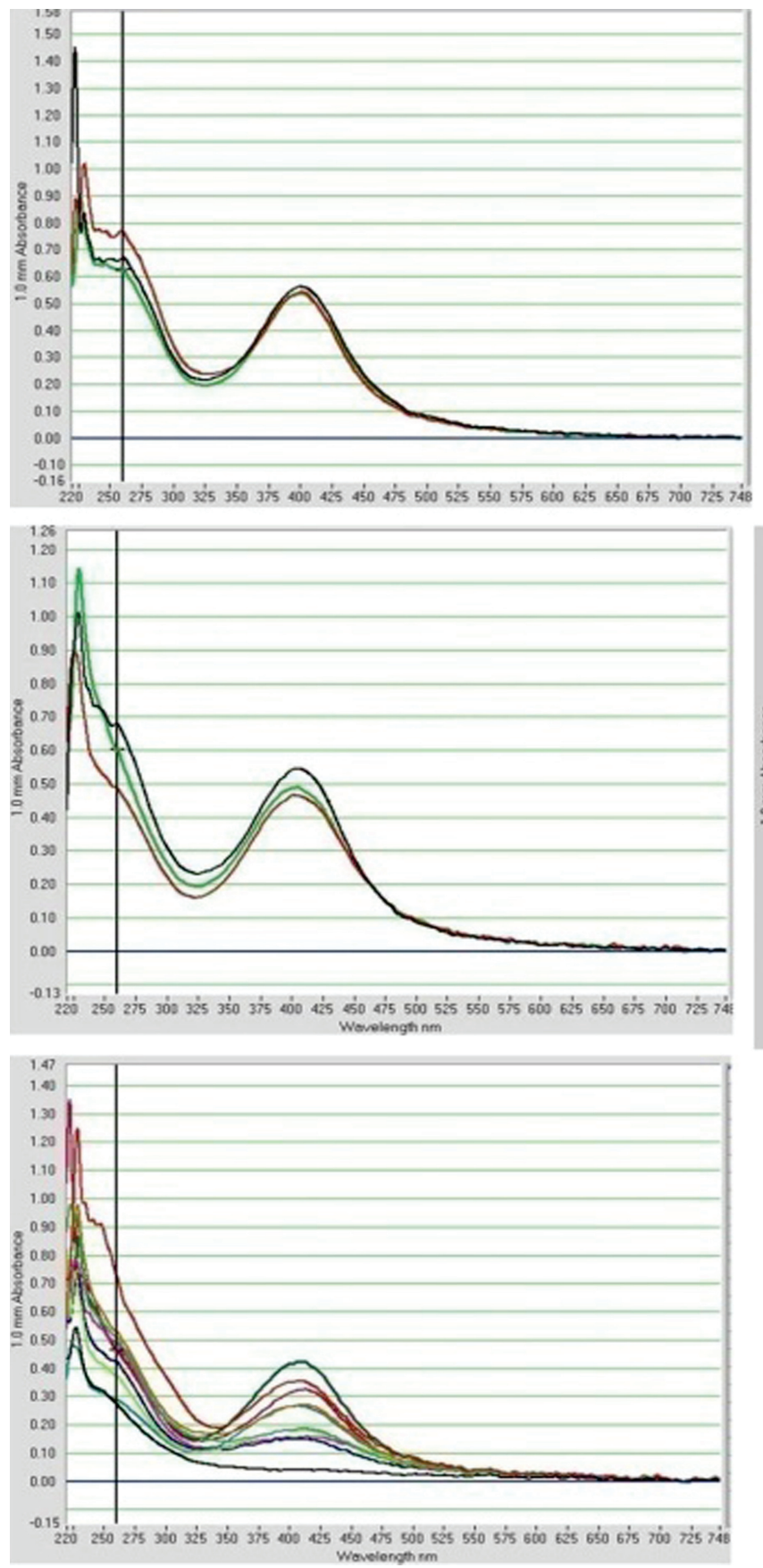

Fig. 1 : UV absorption peak of silver nanoparticles at $420 \mathrm{~nm}$ and $120 \mathrm{~h}$
$30 \mu \mathrm{l}$ of AgNPs solutions and incubated at $37^{\circ} \mathrm{C}$ for $24 \mathrm{hrs}$. Water was used in place of AgNPs in the control plates to evaluate the anti bacterial activity of AgNPs.

\section{Results and Discussion}

Twenty five culture filtrates of Aspergillus niger isolates were mixed with $\mathrm{AgNO}_{3}$ solution to select the potential isolates for
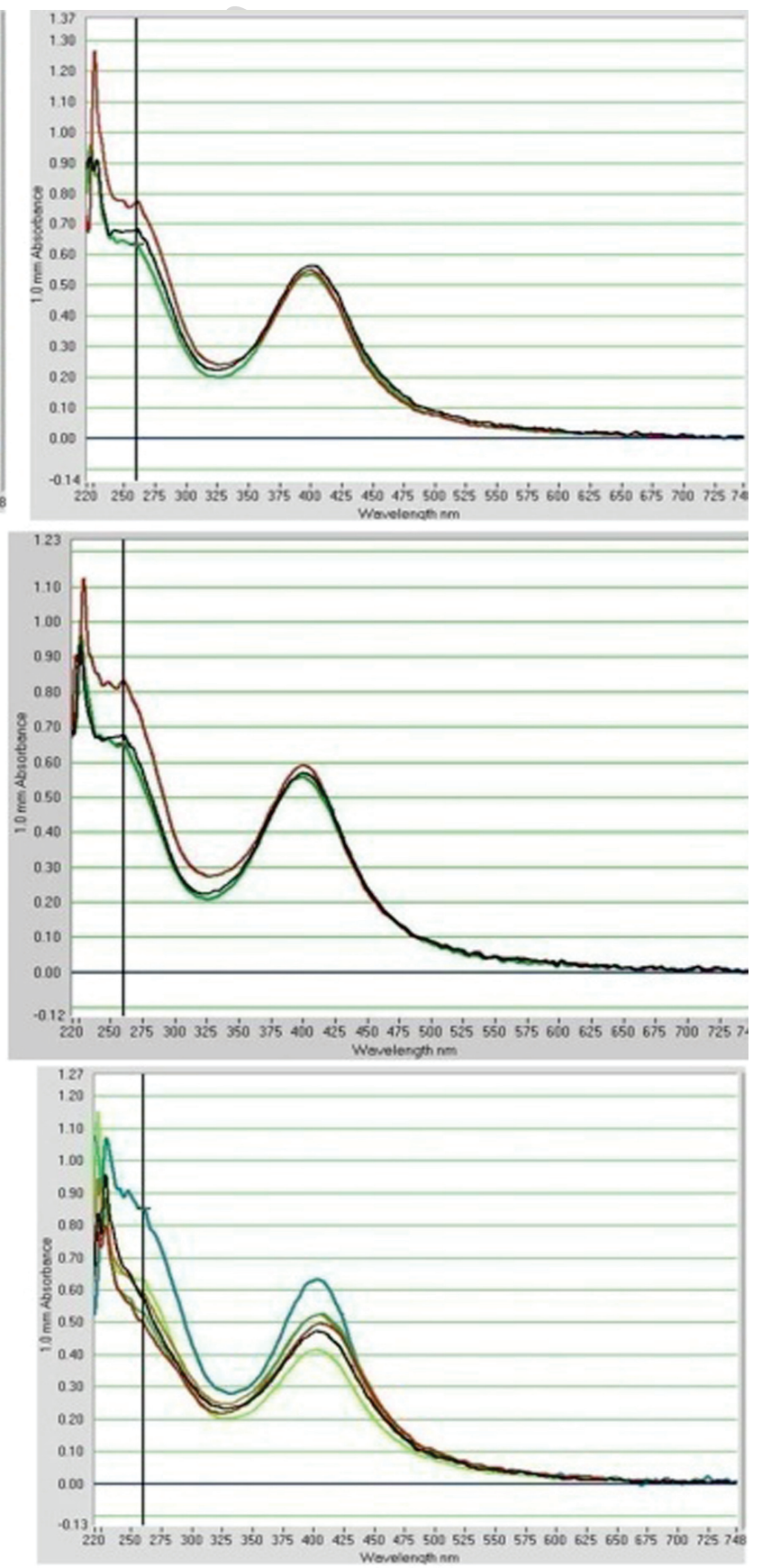

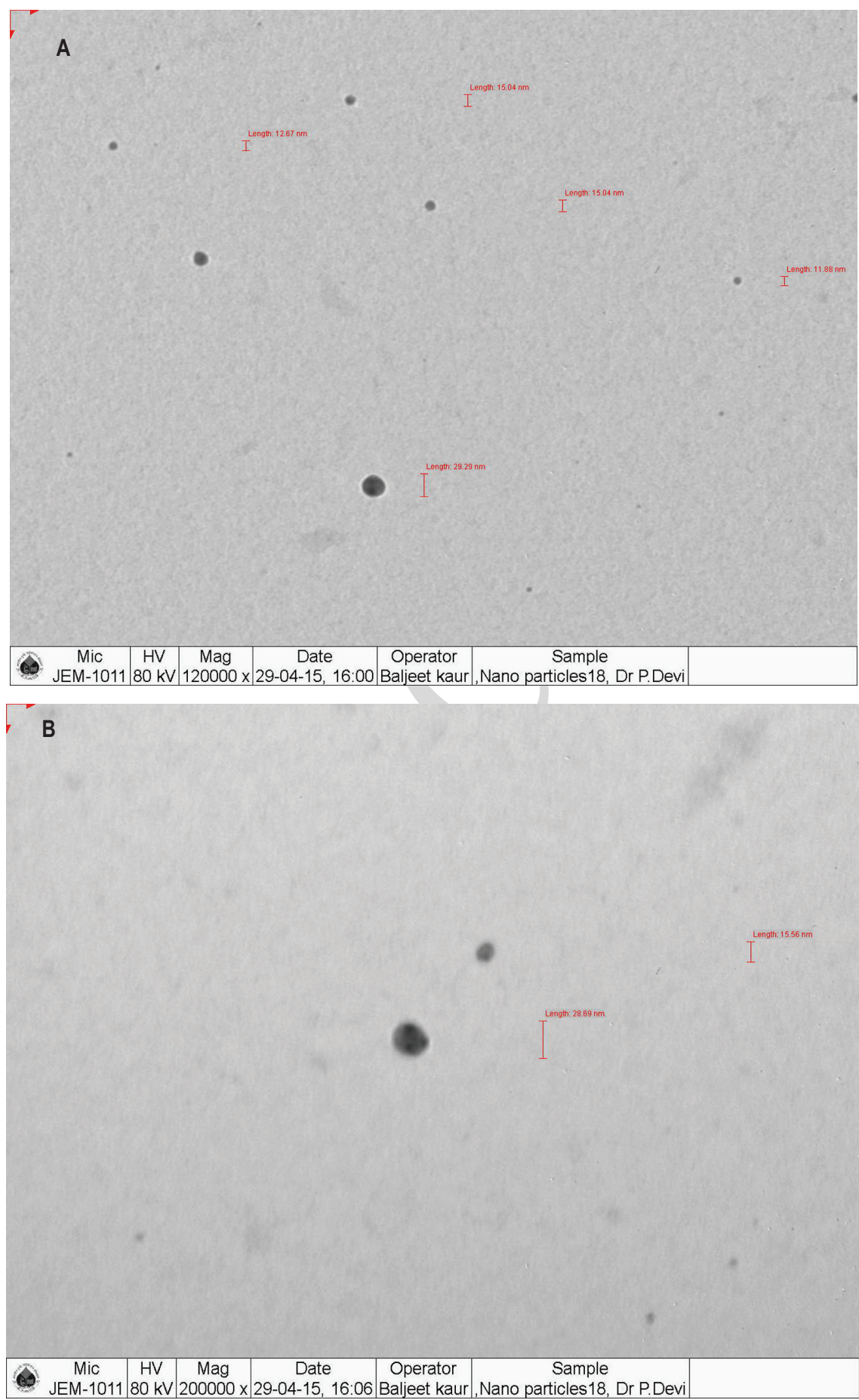

Fig. 2 : Transmission electron microscopy of silver nanoparticles biosynthesized by A-18 and A- 25 isolates of Aspergillus niger

the production of silver nanoparticles. The change in colour from transparent to brown was observed brown at 10 hrs due to deposition of silver nanoparticles, whereas the fungal supernatant (positive control) retained its original colour which denotes production of silver nanoparticles, and color intensity varied due to increasing quantity of nanoparticles. The silver nitrate treated fungal supernatant turned dark. The unreacted fungal biomass retained their original colour and reacted fungal biomass turned into dark brown colour. The UV-Vis reading of fungal biomass of Aspergillus niger treated with $\mathrm{AgNO}_{3}$ is given in Table 1. The 
Table 1: UV-vis absorption values of silver nanoparticles produced by $A$. niger at various time intervals

\begin{tabular}{|c|c|c|c|c|c|c|c|c|c|c|c|}
\hline \multirow{2}{*}{$\begin{array}{l}\text { Culture } \\
\text { No. }\end{array}$} & \multirow{2}{*}{$\begin{array}{l}\text { ITCC } \\
\text { No. }\end{array}$} & \multicolumn{2}{|l|}{ Day 1} & \multicolumn{2}{|l|}{ Day 2} & \multicolumn{2}{|l|}{ Day 3} & \multicolumn{2}{|l|}{ Day 4} & \multicolumn{2}{|l|}{ Day 5} \\
\hline & & $\begin{array}{l}380 \\
\mathrm{~nm}\end{array}$ & $\begin{array}{l}420 \\
\mathrm{~nm}\end{array}$ & $\begin{array}{l}380 \\
\mathrm{~nm}\end{array}$ & $\begin{array}{l}420 \\
\mathrm{~nm}\end{array}$ & $\begin{array}{l}380 \\
\mathrm{~nm}\end{array}$ & $\begin{array}{l}420 \\
\mathrm{~nm}\end{array}$ & $\begin{array}{l}380 \\
\mathrm{~nm}\end{array}$ & $\begin{array}{l}420 \\
\mathrm{~nm}\end{array}$ & $\begin{array}{l}380 \\
\mathrm{~nm}\end{array}$ & $\begin{array}{l}420 \\
\mathrm{~nm}\end{array}$ \\
\hline$A-1$ & 6359 & 0.394 & 0.469 & 0.379 & 0.427 & 0.411 & 0.456 & 0.397 & 0.438 & 0.392 & 0.431 \\
\hline$A-2$ & 6370 & 0.094 & 0.097 & 0.072 & 0.051 & 0.066 & 0.038 & 0.042 & 0.039 & 0.037 & 0.043 \\
\hline A-3 & 6409 & 0.495 & 0.498 & 0.485 & 0.484 & 0.483 & 0.477 & 0.483 & 0.481 & 0.471 & 0.468 \\
\hline$A-4$ & 6410 & 0.240 & 0.363 & 0.245 & 0.392 & 0.236 & 0.374 & 0.305 & 0.336 & 0.331 & 0.342 \\
\hline$A-5$ & 6438 & 0.172 & 0.371 & 0.182 & 0.384 & 0.162 & 0.246 & 0.164 & 0.181 & 0.163 & 0.172 \\
\hline A-6 & 6503 & 0.180 & 0.375 & 0.188 & 0.375 & 0.184 & 0.390 & 0.262 & 0.237 & 0.227 & 0.236 \\
\hline A-7 & 6517 & 0.388 & 0.457 & 0.398 & 0.427 & 0.419 & 0.478 & 0.420 & 0.479 & 0.407 & 0.469 \\
\hline$A-8$ & 6543 & 0.418 & 0.483 & 0.178 & 0.216 & 0.243 & 0.297 & 0.453 & 0.487 & 0.450 & 0.473 \\
\hline A-9 & 6560 & 0.330 & 0.356 & 0.322 & 0.346 & 0.291 & 0.301 & 0.279 & 0.293 & 0.278 & 0.289 \\
\hline$A-10$ & 6561 & 0.445 & 0.512 & 0.454 & 0.505 & 0.447 & 0.494 & 0.449 & 0.499 & 0.438 & 0.486 \\
\hline$A-11$ & 6614 & 0.479 & 0.511 & 0.517 & 0.532 & 0.313 & 0.374 & 0.484 & 0.506 & 0.483 & 0.507 \\
\hline$A-12$ & 6642 & 0.467 & 0.525 & 0.458 & 0.507 & 0.437 & 0.479 & 0.489 & 0.537 & 0.480 & 0.526 \\
\hline$A-13$ & 6662 & 0.487 & 0.557 & 0.513 & 0.554 & 0.504 & 0.538 & 0.468 & 0.508 & 0.468 & 0.502 \\
\hline$A-14$ & 6677 & 0.535 & 0.539 & 0.419 & 0.471 & 0.418 & 0.461 & 0.443 & 0.477 & 0.425 & 0.468 \\
\hline$A-15$ & 6719 & 0.455 & 0.498 & 0.364 & 0.392 & 0.368 & 0.384 & 0.364 & 0.382 & 0.351 & 0.372 \\
\hline$A-16$ & 6738 & 0.197 & 0.270 & 0.398 & 0.434 & 0.431 & 0.434 & 0.374 & 0.409 & 0.400 & 0.436 \\
\hline$A-17$ & 6742 & 0.428 & 0.443 & 0.426 & 0.450 & 0.434 & 0.456 & 0.406 & 0.425 & 0.398 & 0.432 \\
\hline$A-18$ & 6775 & 0.492 & 0.540 & 0.518 & 0.542 & 0.489 & 0.514 & 0.486 & 0.515 & 0.477 & 0.503 \\
\hline$A-19$ & 6847 & 0.390 & 0.510 & 0.472 & 0.514 & 0.448 & 0.484 & 0.393 & 0.511 & 0.383 & 0.500 \\
\hline A-20 & 6860 & 0.280 & 0.304 & 0.452 & 0.485 & 0.448 & 0.488 & 0.438 & 0.477 & 0.466 & 0.507 \\
\hline A-21 & 7122 & 0.478 & 0.474 & 0.500 & 0.486 & 0.458 & 0.444 & 0.464 & 0.452 & 0.456 & 0.440 \\
\hline A-22 & 7056 & 0.474 & 0.456 & 0.486 & 0.466 & 0.469 & 0.447 & 0.468 & 0.448 & 0.472 & 0.450 \\
\hline A-23 & 7132 & 0.450 & 0.526 & 0.439 & 0.520 & 0.463 & 0.539 & 0.451 & 0.535 & 0.441 & 0.529 \\
\hline A-24 & 7136 & 0.298 & 0.311 & 0.361 & 0.357 & 0.351 & 0.354 & 0.342 & 0.344 & 0.352 & 0.350 \\
\hline A-25 & 5579 & 0.522 & 0.587 & 0.542 & 0.584 & 0.544 & 0.576 & 0.540 & 0.568 & 0.523 & 0.547 \\
\hline
\end{tabular}

highest absorption band was found in the isolate A-25 followed by A-18. The spectrum clearly showed increase in the intensity of silver nitrate solution, indicating synthesis of increased silver nanoparticles with increasing time (Fig. 1). Some more details including morphology and size of silver nanoparticles synthesized by Aspergillus nigerisolates (A-18 and $\mathrm{A}-25)$ were studied through Transmission electron microscopy (Fig. 2). The particles were isotropic and spherical and mono disperses and the size varied from 3-25 nm. The chemical functional groups were determined by IR spectroscopic analysis in the sample. Different functional groups absorb characteristic frequencies of infrared radiation. The nanoparticles of Aspergillus niger isolate (A-25) were analysed by FTIR spectrum which showed the presence of band at 1636,2121 and $3283 \mathrm{~cm}^{-1}$, the bands at $1636 \mathrm{~cm}^{-1}$ corresponds to primary amine $\mathrm{NH}$ band (Fig. 3).

Further, the bio-efficacy of silver nanoparticles was tested against plant pathogenic bacteria viz., Xanthomonas citri and Ralstonia solanacearum with well diffusion method. The antibacterial activity of silver nanoparticles produced using Aspergillus niger was found maximum in the isolates $A-18$ and $A$ 25 with an inhibition zone ranging from $2.0-3.0 \mathrm{~cm}$ (Fig. 4).
Plants, bacteria and fungi showed the capability of nanosizing of metal ions and were effectively used for controlling other organisms. The nano-sized silver particles (AgNPs) biosynthesized from Nocardiopsis dassonvillei bacteria inhibited $50 \%$ growth of Fusarium solani, F. oxysporum, Alternaria alternata and Rhizoctonia solani at 1.25, 3.23, 4.3 and $9.2 \mathrm{ng} \mathrm{ml}^{-1}$, respectively (Abdel-Megeed et al., 2015). The silver nanoparticles from the root extracts of Catharanthus roseus showed potential larvicidal activity against larvae of Aedes aegypti and Culex quinquefasciatus (Rajagopal et al., 2015). Howeves, reports on the fungal mediated silver nanoparticle synthesis are meagre (Bhainsa and D'Souza, 2006, Kathiresan et al., 2009).

The excitation of surface Plasmon vibrations is a distinctive character which determines the presence of silver nanoparticles. The nanoparticles were produced immediately after silver ions were added to the culture filtrate. Reduction of silver ions was resulted as changed in the colour intensity of culture filtrate was directly proportional to the increasing number of nanoparticles formed. It has been reported that nano-sizing of silver ions were due to the action of reducing agents such as enzyme reductase and electron shuttle quinine 


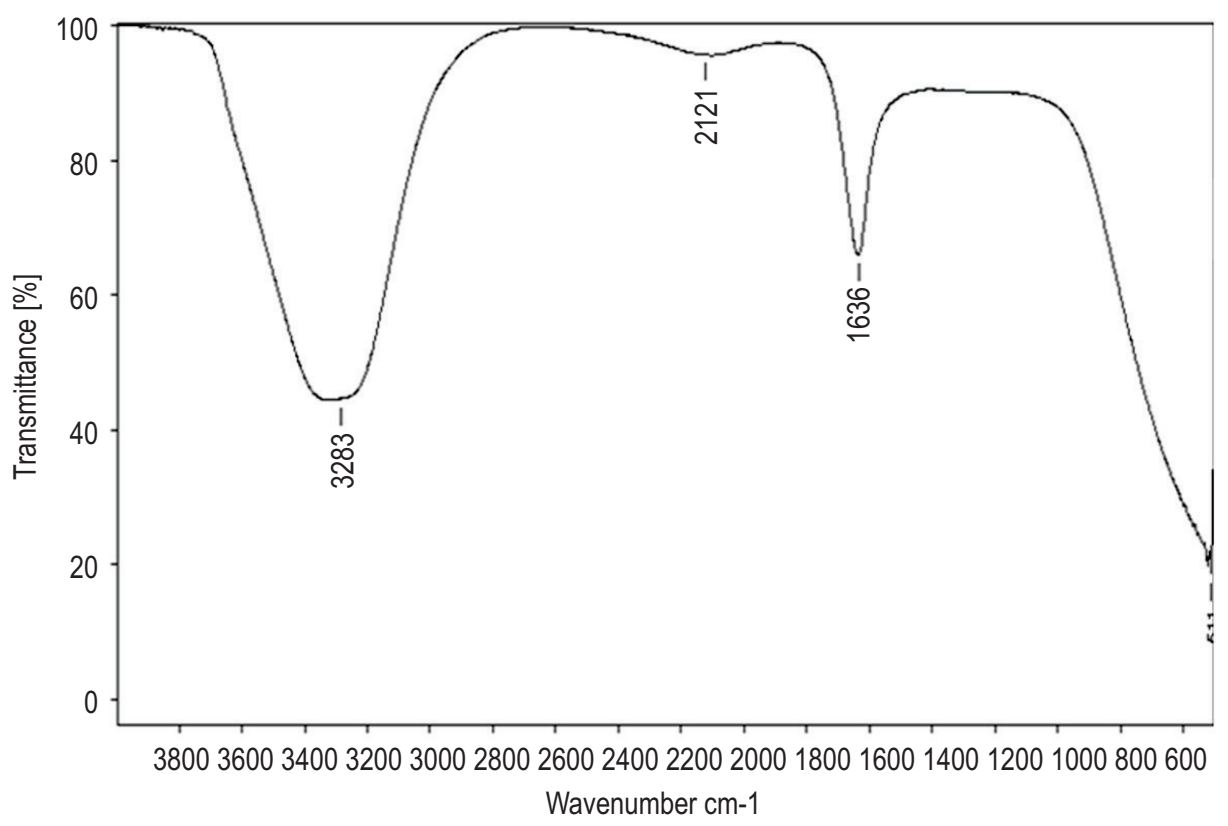

Fig. 3 : FTIR spectrum of silver nanoparticles produced by using Aspergillus niger isolates (A-25)
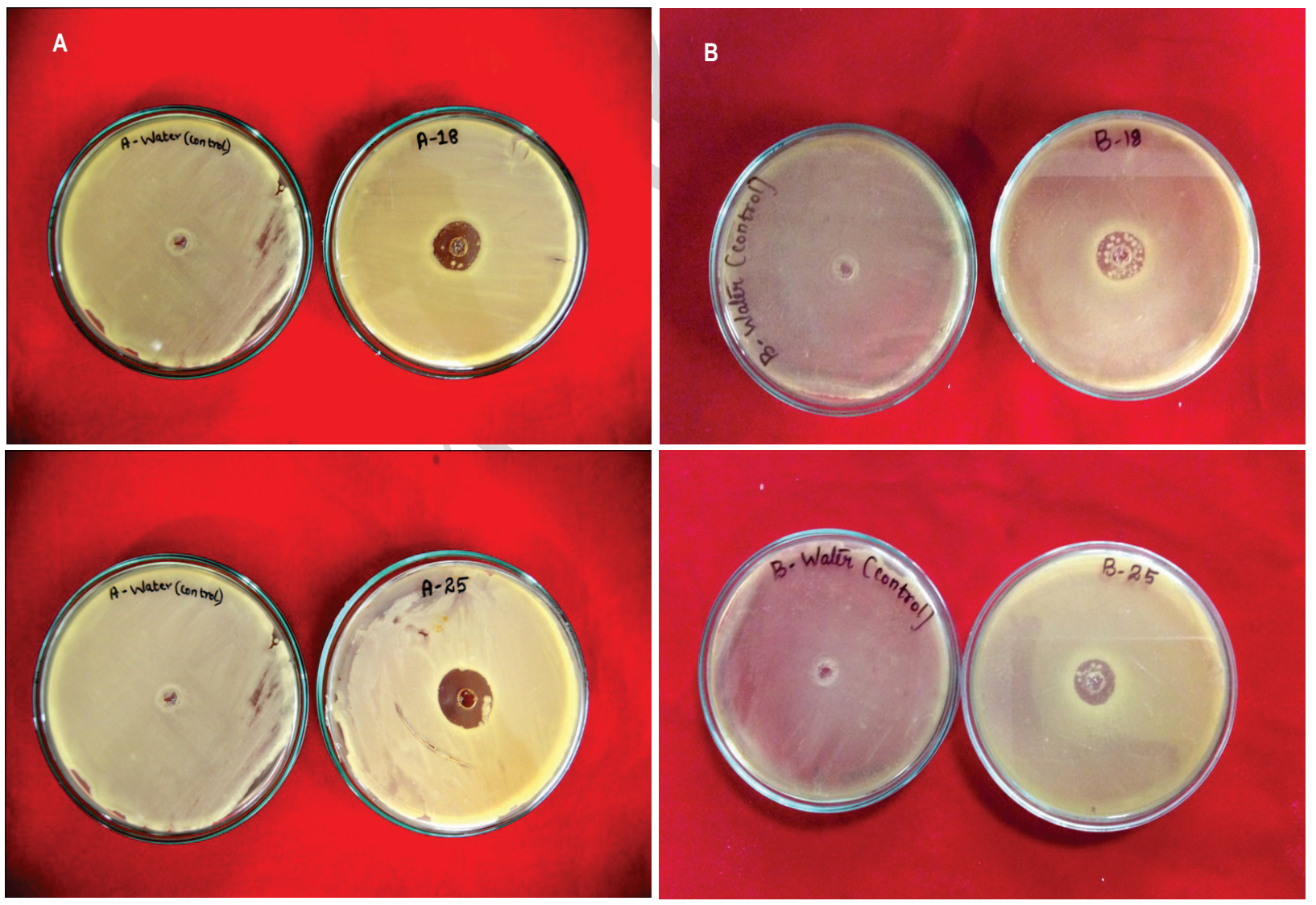

Fig. 4 : Zone of inhibition in the plates treated with silver nanoparticles of $A$. niger against (A): Xanthomonas citri; (B): Ralstonia solanacearum 
(Prameeladevi et al., 2013). An extra-cellular biosynthesis of silver nanoparticles by Aspergillus niger was proved in this study through the change in the colour of the mixer of silver ion and culture filtrate solution from colourless to brown. In the current study, $120 \mathrm{hrs}$ time was taken for complete transformation of metal ions to silver nanoaprticles, Roweves maximum production was observed after 24 hrs of incubation. Balaji et al. (2009) and Shaligram et al. (2009) studied size, shape, texture and arrangement of silver nanoparticles through Transmission electron microscope (TEM). The production of mono dispersed silver nanoparticles by using Fusarium oxysporum and their stability up to four months were reported (Ahmad et al., 2003). The mono-dispersed and spherical nano particles synthesized by $A$. niger were observed in the microphotographs of TEM in our studies. The size ranged from 3-25 nm. FTIR spectroscopic studies established that the carbonyl groups and peptides have strong capability to bind metal ion. The metallic nanoparticles were covered with proteins to avoid clumping in the medium. Recently, it has been reported that the fungal originated molecules maintains stability of silver nanoaparticles (Kamil et al., 2017).

The synthesis of SNP using A. niger is reported. The nano particles were characterised by UV-Vis, TEM and FTIR analyses. Maximum SNP production was observed in culture filtrate of Isolate A25. Crystalline nature of nanoparticles is evident for bright circular spots of 3-25 nm. It is proved from the study that the nanoparticles produced from $A$. niger can be used for the management of bacterial diseases caused by Xanthomonas citri and Ralastonia solanacearium.

\section{Acknowledgments}

The authors thank the Head, Division of Plant Pathology, Indian Agricultural Research Institute, New Delhi for providing the facilities. Authors are also thankful to the Indian Council of Agricultural Research for the financial support.

\section{References}

Abdel-Megeed, A., E.N. Sholkamy, A.A. Alarfaj, A.A. Mostafa, H.H. Alkhamis, A.S. Abdel-Aty and M.M.M. Ahmad: Proficiency of biosynthesized silver nanoparticles as a fungicide against selected damping off causing fungi. J. Environ. Biol., 36, 10451049 (2015).

Ahmad, A., P. Mukherjee, S. Senapati, D. Mandal, I.M. Khan, R. Kumar and M. Sastry: Extracellular biosynthesis of silver nanoparticles using the fungus Fusarium oxysporum. Colloid Surface B, 28, 313318 (2003).

Balaji, D.S., S. Basavaraja, R. Deshpande, D. Bedremahesh, B.K. Prabhakaran and A. Venkataraman : Extracellular biosynthesis of functionalized silver nanoparticles by strains of Cladosporium cladosporioides fungus. Colloid Surface B, 68, 88-92 (2009).

Bhainsa, K.C and S.F. D'Souza: Extracellular biosynthesis of silver nanoparticles using the fungus Aspergillus fumigatus. Colloids Surface B, 47, 160-164 (2006).
Chan, S. and M. Mat Don: Characterization of Ag nanoparticles produced by white-rot fungi and its in vitro antimicrobial activities. Int. Arabic J. Antimicrob. Agents, 2, (2012). ("http://doi.org/10.3823/717"lt"_ blank" 10.3823/717).

Gitanjali, B. S. and A. M. Chavan: Fusarium semitectum mediated extracellular synthesis of silver nanoparticles and their antibacterial activity. Int. J. Biomed. Adva. Res., 5, 348-351 (2014).

Kamil, D., T. Prameeladevi, S. Ganesh, N. Prabhakaran, R. Naresh kumar and S.P. Thomas: Green synthesis of silver nanoparticles by entomopathogenic fungus Beauveria bassiana and their bioefficacy against Mustard aphid (Lipaphis erysimi Kalt.). Indian J. Exp. Biol., 55, 555-561 (2017).

Kathiresan, K., S. Manivannan, M.A. Nabeel and B. Dhivya: Studies on silver nanoparticles synthesized by a marine fungus, Penicillium fellutanum isolated from coastal mangrove sediment. Colloid Surface B, 71, 133-137 (2009).

Li, W.R., X.B. Xie, Q.S. Shi, S.S. Duan, Y.S. Ou-Yang and Y.B. Chen: Antibacterial effect of silver nanoparticles on Staphylococcus aureus. Biometals, 24, 135-141 (2011).

Morones, J.R., J.L. Elechiguerra, A. Camacho and J.T. Ramirez: The bactericidal effect of silver nanoparticles. Nanotechnology, 16, 2346-2353 (2005).

Prameeladevi, T., S. Kulanthaivel, D. Kamil, J.L. Borah, N. Prabhakaran and N. Srinivasa: Biosynthesis of silver nanoparticles from Trichoderma species. Indian J. Exp. Biol., 51, 543-547 (2013).

Rai, M., A. Yadav and A. Gade: Silver nanoparticles as a new generation of anti microbials. Biotechnol. Adv., 27, 76-83 (2009).

Rai, M.K., S.D. Deshmukh, A.P. Ingle and A.K. Gade: Silver nanoparticles: The powerful nanoweapon against multidrugresistant bacteria. J. Appl. Microbiol., 112, 841-852 (2012).

Rajagopal, T., A.Jemimah, P. Ponmanickam and M. Ayyanar: Synthesis of silver nanoparticles using Catharanthus roseus root extract and its larvicidal effects. J. Environ. Biol., 36, 1283-1289 (2015).

Roe, D., B. Karandikar, N. Bonn-Sevage, B. Gibbins and J.B. Roullet: Antimicrobial surface functionalization of plastic catheters by silver nanoparticles. J. Antimicrob. Chemoth., 61, 869-876 (2008).

Sastry, M., A. Ahmad, M.I. Khan and R. Kumar : Biosynthesis of metal nanoparticles using fungi and actinomycete. Curr. Sci., 85, 162170 (2003).

Shaligram, N.S., M. Bule, R. Bhambure, R.S. Singhal, S.K. Singh, G. Szakacs and A. Pandey: Biosynthesis of silver nanoparticles using aqueous extract from the compactin producing fungal strain. Process Biochem., 44, 939-943 (2009).

Shrivastava, S., T. Bera, A. Roy, G. Singh, P. Ramachandrarao and D. Dash: Characterization of enhanced antibacterial effects of novel silver nanoparticles. Nanotechnology, 18, 103-112 (2007).

Singh, P. and R. Balaji: Biological, synthesis and characterization of silver nanoparticles using the fungus Trichoderma harzianum. Asian J. Exp. Biol. Sci., 2, 600-605 (2011).

Verma, A.K., V. Kumar, S. Agarwal, A. Leekha, A. Tyagi, I. Moin and D. Gupta: Interplay of immune response and oxidative stress induced by chitosan nanoparticles to possibly combat inflammation. Worl. Res. J. of Bios., 1, 028-034 (2013).

Vigneshwaran, N., N.M. Ashtaputre, P.V. Varadarajan, R.P. Nachane, K.M. Paralikar and R.H. Balasubramanya: Biological synthesis of silver nanoparticles using the fungus Aspergillus flavus. Mater. Let., 61, 1413-1418 (2007).

Zeng, G., D. Huang, G. Huang, T. Hu, X. Jiang, C. Feng, Y. Chen, L.Tang and $\mathrm{H}$. Liu: Composting of lead contaminated solid waste with inocula of white-rot fungus. Biores. Technol., 98, 320-6 (2007). 